\title{
Implicações da ação docente sobre questões de sexualidade e gênero na escola
}

RESUMO: O presente artigo tem como foco discutir o papel do professor diante de questões sobre sexualidade e gênero, quando estas emergem no âmbito escolar. Considera-se que, na escola, professoras e professores, na condição de importantes referenciais para meninos e meninas, no que tange a sua formação, devem atentar para tais questões, a fim de tratá-las com a necessária atenção e o devido cuidado que merecem. A forma como sexualidade e gênero são encarados por professores e professoras pode influenciar, também, a postura de alunos e alunas diante de questões da mesma natureza.

PALAVRAS-CHAVE: Gênero. Sexualidade. Função do professor. Escola.

\section{Introdução}

O olhar sobre a sexualidade é sempre rodeado de tabus e preconceitos. Questões referentes a gênero tendem a ser tratadas de forma ingênua, considerando-as naturais. A sexualidade compreende, contudo, o (re)conhecimento de si mesmo, de limites e possibilidades na busca pelo prazer e está subjacente ao comportamento dos sujeitos nas relações sociais; já o gênero trata dos padrões comportamentais socialmente estabelecidos. A partir desse entendimento, sexualidade e gênero estão imersos no cotidiano da vida social, fazendo-se presentes "[...] nas múltiplas instâncias sociais, nas diferentes práticas, espaços e instituições, através dos símbolos, normas, doutrinas, através das intricadas redes de relações entre os sujeitos" (LOURO, 1995, p. 3), constituindo-se faces imbricadas de um mesmo processo - o processo de formação da pessoa humana.

É com base nessa premissa, que se pretende tecer, aqui, uma discussão sobre os temas, articulada à figura de professores e professoras, visto que, na escola, espaço social por excelência, questões dessa natureza são freqüentes e, dada a sua importância para o processo educativo, não podem passar despercebidas.

Railda Maria Bispo de Jesus Professora/Tutora da Unifacs raildamaria@yahoo.com.br 


\title{
Sexualidade: Princípio de bem-estar
}

A visão que, por extenso, se tem sobre sexualidade é reduzida, na maioria das vezes, ao estudo e análise da biologia humana, no sentido de desvendar os segredos da reprodução e dos aparelhos reprodutivos masculino e feminino, alertando sobre gravidez e/ou DST. Tratada dessa forma, a sexualidade fica limitada à mera explicação e entendimento sobre contracepção e/ou prevenção DST ou resumida a um jogo de perguntas e repostas sobre a relação sexual em si. Nesse contexto, Fagundes (2005, p.14) considera que

\begin{abstract}
Sexualidade e reprodução são processos que se expressam graças a órgãos específicos do ser humano e, por isso, têm uma estreita relação, mas não significam a mesma coisa. Reprodução é o processo pelo qual a vida é gerada [...] Sexualidade é muito mais do que ter um corpo apto para procriar e apresentar desejos sexuais; pressupõe intimidade, afeto, emoções, sentimentos e bem-estar individual decorrentes, inclusive, da história de vida de cada pessoa.
\end{abstract}

Nessa perspectiva, sexualidade compreende formas, jeitos, maneiras de as pessoas expressarem a busca pelo prazer, as quais se fazem presentes em seus pensamentos e emoções, em suas ações e interações. A sexualidade se manifesta, então, a todo o momento, em todo e qualquer espaço em que o sujeito, meninos e meninas, homens e mulheres, está inserido.

Percebe-se, pois, que a sexualidade não se situa, apenas, no campo da biologia, não se realiza somente num corpo sexuado, mas está relacionada, também, a fatores outros que, tal qual o biológico, fazem parte da vida dos sujeitos. Fagundes (2005, p. 17) assevera que a sexualidade "[...] se associa aos componentes biológicos e psicológicos [...]" e "[...] se traduz pelo social, histórico e cultural [...] plasmada pela linguagem, normas e valores vigentes nas sociedades, em diferentes épocas". Pode-se afirmar, então, que a sexualidade está condicionada a fatores internos e externos ao ser humano, os quais, num processo de influência mútua, contribuem para o contexto de vida de cada indivíduo e, conseqüentemente, para a forma como a sua personalidade será desenvolvida.

A partir dessas elaborações, depreende-se que as situações experimentadas pelos sujeitos, durante suas fases de desenvolvi- 
mento (infância, adolescência, idade adulta e senilidade), são tomadas como referenciais nas várias dimensões da vida do ser humano, incluindo, aí, a sexualidade na forma como ela pode ser concebida, internalizada e manifestada.

Entende-se, dessa forma, que se o assunto é rodeado de culpas, medos, pressões e repressões, provocam-se mal-estar, rubores e constrangimentos ao ser abordado; tende-se a evitá-lo ou a discuti-lo "[...] em conversas de voz baixa, com reservas e com poucas pessoas". (LOURO, 2001, p. 133). Se, por outro lado, compreende-se que a sexualidade é "[...] elemento constitutivo da pessoa, é dimensão e expressão da personalidade" (FAGUNDES, 2005, p. 14), desconstroem-se preconceitos, deboches, malícias com que o tema é tratado; desfazem-se os "[...] dualismos: saudável/doentio, normal/anormal (ou desviantes), heterossexual/homossexual, próprio/impróprio, benéfico/nocivo, etc." (FAGUNDES, 2005, p. 14), rompendo com idéias e representações simplistas sobre o assunto.

Pode-se entender, assim, que cada sujeito possui uma forma singular de exprimir a sua sexualidade, não havendo, portanto, certo ou errado, mas, apenas, diferente(s) maneira(s) de manifestá1a. Nesse sentido, é preciso libertar-se de estereótipos, de conceitos sociais previamente construídos, os quais conduzem o pensar e o agir sobre mundo, a um único sentido, a uma única direção.

Para se romper, contudo, com esse tipo de pensamento, fazse necessário tanto quanto discutir sexualidade, discutir, particularmente, questões sobre gênero, pois as representações socialmente concebidas acerca do feminino e do masculino repercutem na(s) forma(s) de expressão da sexualidade de meninos e meninas, de homens e mulheres.

\section{Gênero: elemento constitutivo das relações sociais}

É evidente que homens e mulheres, meninos e meninas vivem engendrados por padrões de postura e comportamento ditados pela sociedade da qual fazem parte. O que ainda não se faz claro é que tais modelos não passam de produtos emanados da própria sociedade e que são, também, por ela amplamente disseminados, apontando para uma visão parcial e limitada do mundo.

É nesse sentido que gênero vem sendo estudado, desde a intensificação das produções sobre o tema, ou seja, apesar de o as- 
sunto ser analisado sob óticas distintas e de o termo ser considerado polissêmico, as produções convergem para a afirmativa de que gênero é, indubitavelmente, uma construção social. Esta dinâmica, contudo, não se dá independente de um dado tempo e espaço, muito menos sem a elaboração de mecanismos que regulam as práticas aí estabelecidas. Infere-se, pois, neste contexto, que gênero é marcadamente "[...] produto de um longo trabalho histórico e cultural de construção teórica e prática sobre os corpos e sobre as mentes". (FAGUNDES, 2005, p.10). Isso implica dizer que a dimensão psicológica do indivíduo é trabalhada, fazendo-se interiorizar concepções criadas acerca do que é ser homem e do que é ser mulher. Dessa forma, meninos e meninas, homens e mulheres são orientados e orientadas a seguirem padrões, a se revestirem de estereótipos, a manifestarem práticas masculinizantes e feminilizantes, afirmando condições, funções e posições sociais que desfrutam, exercem e ocupam, contribuindo para a sobrevivência e a perpetuação da dicotomia entre os sexos.

O viés essencialista, segundo o qual feminino e masculino nasceram biologicamente com papéis sociais definidos, acabou se firmando no imaginário, no inconsciente coletivo, legitimando e validando representações e idéias préconcebidas sobre os sexos. Assim, enquanto o homem é marcado por características como força, virilidade, explosão e agressividade, as mulheres são tidas como frágeis, maternais, sensíveis, bem-comportadas.

No bojo dessa discussão, pode-se tomar a máxima de Beauvoir (1980, p.9), "[...] ninguém nasce mulher, torna-se mulher", para compreender que ser homem e ser mulher, tendo em vista papéis e representações socialmente concebidos, são aprendizagens imputadas aos sujeitos sociais, as quais sinalizam para formas 1imitadas de agir e pensar, circunscritas ao universo masculino ou ao universo feminino.

Acerca disso, a antropóloga americana Mead (1999), após realizar pesquisa junto a tribos primitivas, constata que as características psicológicas concebidas pelas sociedades ocidentais, e habitualmente ligadas à masculinidade e à feminilidade, existem em sociedades primitivas independentemente do sexo; para a autora,

As diferenças entre indivíduos que são membros de diferentes culturas, a exemplo das diferenças entre indivíduos dentro da mesma cultura, 
devem ser atribuídas quase inteiramente às diferenças de condicionamento, em particular durante a primeira infância, e a forma deste condicionamento é culturalmente determinada. (MEAD, 1999, p.268 e 269).

As aprendizagens referentes à identidade social construída em torno de homens e mulheres se dão nas múltiplas instâncias e espaços que compõem a sociedade, por meio de seus instrumentos de dominação e poder, a exemplo da escola e da educação escolar, respectivamente.

A escola é locus de produção e socialização de saberes e conhecimentos; a educação que aí se desenvolve é um processo sistemático e intencional de formação múltipla dos sujeitos. (LOURO, 1995). Sendo um recorte da sociedade, a escola vive e convive com os entraves e dilemas do contexto a que pertence e, por meio da sua educação, pretende tornar os indivíduos "aptos" para a convivência com os demais, compartilhando, com as novas gerações, códigos, representações, concepções, idéias, enfim, todo o arcabouço histórico e cultural que a sustenta. "[...] Servindo-se de símbolos e códigos, ela afirma o que cada um pode (não pode) fazer, ela separa e institui. Informa o lugar dos pequenos e dos grandes, dos meninos e das meninas". (LOURO, 1997, p. 58).

Ela tende, portanto, a reproduzir a atmosfera social. Como afirmam Bourdieu e Passeron (1992, p. 64),

Todo sistema de ensino institucionalizado (SE) deve as características específicas de sua estrutura e de seu funcionamento ao fato de que lhe é preciso produzir e reproduzir, pelos meios próprios da instituição, as condições institucionais cuja existência e persistência (auto-reprodução da instituição) são necessários tanto ao exercício de sua função própria de inculcação, quanto à realização de sua função de reprodução de um arbitrário cultural do qual ele não é o produtor [...] e cuja reprodução contribui à reprodução das relações entre os grupos ou as classes (reprodução social).

Contudo, diante de movimentos atuais que visam uma sociedade democrática, que pensam e lutam por uma educação para a cidadania, objetivando a construção da consciência crítica e ética, a escola toma forma de espaço operador de mudanças e transformações sociais, sendo um ambiente onde 
[...] não se busca outra coisa senão a permanente reconstrução da vida para maior riqueza, maior harmonia e maior liberdade, dentro do ambiente de transformação e progresso [...]. (TEIXEIRA, 1975, p. 51).

Ela é, portanto, capaz também de imprimir nos sujeitos novas formas de pensar e agir, desmistificando, por exemplo, modelos e padrões de homens e mulheres que pairam sobre a sociedade.

$\mathrm{Na}$ escola, a sala de aula pode ser considerada o espaço privilegiado e propício para instigar e vislumbrar a construção de novas práticas sociais, de novas formas de agir e pensar que se fazem necessárias, pois é lá onde se operacionalizam as práticas educativas que possibilitarão mudanças e transformações sociais. Sendo assim, professoras e professores, na condição de sujeitos que lidam diretamente com o fazer pedagógico da sala de aula e acompanham, sistematicamente, o processo de ensino-aprendizagem, devem atentar para toda e qualquer demanda que traga implicações à formação dos sujeitos, a fim de dar os encaminhamentos que permitam contribuir com o rompimento de estruturas previamente estabelecidas que modelam, limitam e massificam corpos e mentes.

\section{A ação docente diante de questões sobre sexualidade e gênero}

É muito comum, ao universo infantil, brincadeiras de faz-deconta, principalmente, aquelas em que as crianças, meninos e meninas, tendem a imitar seus/suas professores/as, reproduzindo o ambiente escolar do qual fazem parte. Junto às/aos adolescentes, a imagem de detentor do saber e do conhecimento, socialmente concebidas, fazem do professor alguém em quem se pode creditar segurança e credibilidade. Dessa forma, docentes, homens e mulheres, exercem importante função durante o processo de escolarização de crianças e adolescentes, meninos e meninas, tornando-se referenciais em suas vidas, representando, por vezes, o modelo de ser social, homem mulher, que se pretende ser.

Segundo a análise de Louro (2001, p. 92), desde o início dos tempos modernos, o processo educativo escolar se assenta na figura do mestre, entendido aqui como um ser do sexo feminino ou masculino, o qual 
[...] se tornará responsável pela conduta de cada um dos seus estudantes, cuidando para que esse carregue, para além da escola, os comportamentos e as virtudes que ali aprendeu. Para que isso aconteça, não basta que o mestre seja conhecedor dos saberes que deve transmitir, mas é preciso que seja, ele próprio, um modelo a ser seguido.

Nesse sentido, percebe-se que tudo que é feito e dito por professores e professoras pode ser relevante para seus/as alunos e alunas, podendo repercutir em suas mentes, provocando reflexões que permitam mudanças em sua forma de agir e pensar.

Dito isto, docentes, homens e mulheres precisam atentar para as muitas questões que se fazem presentes no cotidiano escolar, pois a forma como abordam, procedem e se posicionam diante delas pode influenciar a forma como seus alunos e alunas se comportam diante das mesmas.

Questões sobre sexualidade podem ser, aí, incluídas, afinal elas estão

[...] queira-se ou não, na escola. Elas fazem parte das conversas dos/as estudantes, elas estão nos grafites dos banheiros, nas piadas e brincadeiras, nas aproximações afetivas, nos namoros; e não apenas aí, elas estão também de fato nas salas de aula -assumidamente ou não- nas falas e atitudes das professoras, dos professores e estudantes. (LOURO, 1997, p.131).

Por não ser vista e tratada socialmente, com naturalidade, como qualquer outro assunto, a sexualidade é sufocada e entendida como transgressão às regras, aos valores, às normas de conduta; ao surgir no âmbito social tende a ser de maneira camuflada, sub-repticiamente.

Acerca das questões de gênero, de acordo com Lima (2000, p. 12), é, também, na escola que elas tomam corpo, se formalizam, sedimentam-se e dão bases "[...] à divisão de papéis sociais exercidos por homens e mulheres". Esses papéis influenciam as múltiplas dimensões da vida dos sujeitos, delineando, inclusive, sua sexualidade.

Nesse contexto, a figura feminina, por exemplo, submetida, historicamente, à situação de subserviência e passividade, tida como frágil, emotiva, sensível, tende-se lhe imputar aprendizagens de gestos contidos, restritos e recatados à sua personalida- 
de, as quais reprimem e, por vezes, tolhem a expressão da sua sexualidade; assim ela deve se apresentar e se comportar socialmente. Já à figura masculina, incentiva-se o aguçamento de seus instintos, estimula-se exibição de sua força, seu vigor, sua virilidade; permite-se que sua sexualidade seja expressa com total liberdade. É a moral sexual diferenciada que, resistindo aos tempos, favorece as experiências sexuais masculinas, restringindo a sexualidade feminina. (BASSANEZI, 1997, p.608-609).

O ambiente escolar, por vezes, representa para os atores sociais que aí convivem, meninos e meninas, o único canal seguro e confiável para tratar sobre o tema da sexualidade, visto que nem sempre se desfruta de uma estrutura familiar que se mostre aberta ao assunto, até por conta da forma como ele é socialmente abordado: restringindo-se ao aspecto genital, limitada ao ato sexual. Por conta disso, a vergonha e a timidez impedem, também, que se busquem os espaços que oferecem o suporte e a infraestrutura adequados, para se sanar dúvidas e inquietações.

Dessa forma, a fim de que concepções errôneas e simplistas não continuem sendo propagadas, fazendo com que a sexualidade se mantenha na obscuridade e no campo da obscenidade, é preciso que professores e professoras estejam preparados/as para discutir o tema sob uma perspectiva mais ampla, fazendo-se perceber que a sexualidade é mais uma dentre as dimensões humanas existentes, desconstruindo, assim, tabus e preconceitos que a cercam. É com a mesma postura crítica que se faz necessário tratar de questões referentes a gênero, pois, tendo em vista a sua construção social, é imprescindível não permitir, na escola, a (re)produção e manutenção de visões sexistas, dicotômicas e estereotipadas acerca de homens e mulheres. Considerando que a escola atende a crianças e adolescentes de classes, níveis culturais, faixas etárias e etnias distintas, este é lugar propício para o exercício da democracia, no que se refere a aprender a conviver e respeitar as diferenças existentes entre os sujeitos, repudiando qualquer forma de tratamento desigual.

Nesse contexto, faz-se necessário que professores e professoras se instrumentalizem com informações e conhecimentos acerca de questões sobre sexualidade e gênero, para que, ao surgirem, seja possível saber lidar com as mesmas. Assim, cursos de capacitação, aperfeiçoamento e especialização precisam abrir espaço para os temas em sua programação, promovendo seu deba- 
te, discussão e problematização, proporcionando o despertar para questões associadas à temática. Todavia, mais do que serem trabalhados em cursos dessa natureza, é preciso que os currículos de formação de professores/as contemplem sexualidade e gênero no momento de sua concepção e construção, pois, considerando que este é um processo longo de formação, oportuniza-se uma melhor apropriação desses temas, possibilitando uma melhor sensibilização e um melhor aguçamento dos sentidos para percepção dessas questões, tratando situações e problemas de forma pertinente, dando os encaminhamentos possíveis e necessários. Sobre o assunto, Carvalho (2004, p. 28) considera que a "[...] formação docente inicial e continuada deve ampliar os espaços de reflexão sobre a ação docente e empoderar/instrumentar educadoras e educadores para o desafio da reflexão na ação".

Somente com professores e professoras capazes de enfrentar os desafios que ambos os temas trazem será possível mexer nas bases que os sustentam e os estruturam; será possível a professores e professoras instigarem as mentes de crianças, adolescentes, jovens e adultos, contribuindo para uma mudança de mentalidade e para uma nova interpretação e compreensão de representações que envolvem sexualidade e gênero.

Não se trata, aqui, de fazer da escola espaço terapêutico para tratar de questões sobre a sexualidade, muito menos palco de lutas e disputas acirradas entre sexos, mas sim de ressignificar seu papel, respondendo a demandas que emergem da sociedade, bem como da família e da comunidade onde se insere, tratando os temas de forma pertinente, VER quando os mesmos surgem no ambiente escolar. Dessa forma, professores e professoras "[...] precisam estar afinados para que sejam capazes de ver, ouvir, sentir as múltiplas [...]" (LOURO, 1997, p. 59) formas de manifestação e expressão de sexualidade e gênero na organização e no fazer do cotidiano escolar.

Vale ressaltar que a sexualidade, para a Organização Mundial de Saúde $(\mathrm{OMS})^{1}$, junto à manutenção da vida profissional, à convivência familiar e ao lazer fácil, constitui-se um dos indicadores para avaliar a qualidade de vida de uma pessoa. Sobre as relações de gênero, a Organização das Nações Unidas para Infância e Adolescência $(\mathrm{ONU})^{2}$ estabeleceu como uma de suas metas, para este século, promover a igualdade entre os sexos. Dessa maneira, refletir e agir sobre as problemáticas de sexualidade e gênero não
(1) http://www.terra.com.br/istoe/ biblioteca/saudemulher/sexo.htm.

(2) http://www.agende.org.br/ conferencias/metas_milenio/ interna. php?area $=35$. 
devem ser ações isoladas e pontuais, mas devem, sim, permear os processos educativos em todos os momentos e espaços sociais em que acontecem.

\title{
Implications of teaching in issues of sexuality and gender at schools
}

\begin{abstract}
This article presents a discussion on the role of the teacher man or woman, concerning questions on sexuality and gender, that arise at the school environment. It is considered that, at school, teachers, men and women, as important references for students, boys and girls, in what refers to their formation, must be aware of these questions, to aproach them with the necessary attention and care they deserve. The way sexuality and gender are faced by teachers, men and women, can as well influence pupils, girls and boys, attitude towards questions of the same nature.

KEY WORDS: Gender. Sexuality. Teaching function. School.
\end{abstract}

\section{Referências}

AGENDE Ações em Gênero, Cidadania e Desenvolvimento. Metas do milênio. Disponível em: < http://www.agende.org.br/conferencias/metas_milenio/interna.php?area $=35$ > . Acesso em: 28 jun. 2006.

ARAN, Márcia. Os destinos da diferença sexual na cultura contemporânea. Estudos Feministas, Florianópolis, v.11, n. 2, p. 399-422, juldez. 2003.

BASSANEZI, Carla. Mulheres dos anos dourados. In: PRIORI, Ivany Del (Org.). História das mulheres no Brasil. São Paulo: Contexto, 1997. p. 607 - 637.

BEAUVOIR, Simone de. O segundo sexo: experiência vivida. 6. ed. Tradução de Sérgio Millet. Rio de Janeiro: Nova Fronteira, 1980. 500 p

BOURDIEU, Pierre; PASSERON, Jean Claude. A reprodução: elementos para uma teoria do sistema de ensino. Tradução de Reynaldo Bairão. 3. ed. Rio de Janeiro: Francisco Alves, 1992. 238 p. (Educação em questão).

CARVALHO. Maria Eulina Pessoa de. Relações de gênero na escola: lições do projeto de formação em educação não sexista. Lilás: Revista Informativa da Coordenadoria da Mulher, Recife, Ano 3, n.3, jan. p.28-36, 2004.

EM BUSCA de um sexo bem melhor. Disponível em: < http:// www.terra.com.br/istoe/biblioteca/saudemulher/sexo.htm $>$. Acesso em: 28 de junho de 2006.

FAGUNDES, Tereza Cristina Pereira Carvalho. Ensaios sobre educação, sexualidade e gênero. Salvador: Ed. Helvécia, 2005.269 p.

Ensaios sobre identidade e gênero. Salvador: Ed. Helvécia, 2003. 208 p. 
Mulher e pedagogia: um vínculo re-significado. Salvador:

Ed. Helvécia, 2005. 200 p.

FAGUNDES, Tereza Cristina Pereira Carvalho (Org.). Ensaios sobre gênero e educação. Salvador: Universidade Federal da Bahia, 2001. $171 \mathrm{p}$.

JESUS, Railda Maria Bispo de. Aprendendo a ser menina, aprendendo a ser menino: um estudo sobre representações de gênero veiculadas em livros paradidáticos utilizados em classes de alfabetização em escolas públicas e particulares de Salvador. 2005. 50 f. Trabalho de Conclusão de Cursos (Graduação em Pedagogia) - Faculdade de Educação, Universidade Federal da Bahia.

LOURO, Guacira Lopes. Educação e gênero: a escola e a produção do feminino e do masculino. In: SILVA, Luiz Heron da; AZEVEDO, José Clóvis de (Org.). Reestruturação Curricular: teoria e prática no cotidiano da escola. Petrópolis, RJ: Vozes, 1995. p. 32 -36

LOURO, Guacira Lopes. Gênero, sexualidade e educação: uma perspectiva pós-estruturalista. 4. ed. Petrópolis, RJ: Vozes, 1997. 179 p.

LIMA, Maria Ednalva Bezerra de. As relações de gênero e a educação. In: RELAÇÕES de gênero em debate. Recife: Ed. Bagaço, 2000. p. 9-19

MEAD, Margaret. Sexo e temperamento. 4. ed. São Paulo: Perspectiva, 1999. 320 p. (Debates. Antropologia,5)

MORENO, Montserrat. Sexismo na escola: como se ensina a ser menina. São Paulo: Moderna, 2000. 80 p.

PARAÍSO, Marlucy Alves. Gênero na formação docente: campo de silêncio no currículo. Caderno de Pesquisa, n. 102, p. 23-45, nov. 1997.

SABAT, Ruth. Pedagogia cultural, gênero e sexualidade. Estudos Feministas, Florianópolis, v. 9, n. 1, p. 9-21, 2001.

SCOTT, Joan Walach. Gênero: uma categoria útil para a análise histórica. Tradução de Christine Rufino Dobat. Recife: S.O.S. - Corpo, 1991.

SILVA, Tomaz Tadeu da. Documentos de identidade. 2. ed. Belo Horizonte: Autêntica, 2002.

TEIXEIRA, Anísio Teixeira. Pequena introdução a filosofia da educação: escola progressiva ou a transformação da escola.. São Paulo: Nacional, 1975. p. 52-83.

TIEFER, Leonore. Uma perspectiva feminista sobre sexologia e sexualidade. In: GERGEN, M.C. et al. o pensamento feminista e a estrutura do conhecimento. Rio de Janeiro: Rosa dos Tempos, 1993. p. $36-47$.

ZAIDMAN, Claude. Do cotidiano da escola mista ao ideal de co-educação. Estudos Feministas, Florianópolis, v. 8, n.1, p. 251-253, 2000. 